\title{
Reply to the John L. Frater/Analyte stability, instrumentation, and the red blood cell distribution width: Comments on "Red blood cell distribution width and tumor necrosis factor-a for the early prediction of coronary artery lesion in Kawasaki disease: a retrospective study"
}

\author{
Jie $\mathrm{Li}^{1} \cdot$ Huajun $\mathrm{Li}^{2}$ (1)
}

Received: 20 December 2021 / Revised: 20 December 2021 / Accepted: 23 December 2021 / Published online: 28 January 2022

(c) The Author(s), under exclusive licence to Springer-Verlag GmbH Germany, part of Springer Nature 2022

Dear Editor,

We greatly appreciate the readers' comments for our paper published by European Journal of Pediatrics [1]. Below are our responses.

First, red blood cell distribution width (RDW) is a common test item in routine blood analysis. Almost every child with Kawasaki disease would have this necessary test. All blood test in our hospital has strictly unified procedures for collection, storage, transportation, and examination.

Second, every child analyzed in the paper is a hospitalized child, so all blood samples were collected by pediatric nurses in emergency department. Blood samples were collected using test tubes containing EDTA-K2 anticoagulant, and the anticoagulant was mixed in time after collection, which was further kept at room temperature. Professional logistics personnel who transported the specimen would send the blood specimen to the laboratory in the same building within $30 \mathrm{~min}$. The physician in the laboratory verifies that the specimen is qualified and carries out routine blood testing immediately, usually within $30 \mathrm{~min}$. Therefore, from the collection of blood samples to the detection results of all specimens, the fastest time is within $30 \mathrm{~min}$, and the longest is generally no more than $2 \mathrm{~h}$.

Third, the blood analysis of the samples from all children in this paper was conducted using the Sysmex XN-9000 automatic blood cell analyzer in the laboratory department of our hospital. The examination was completed in strict accordance with the operating steps. Also, the laboratory department has a strict quality control system to ensure the reliability of inspection results.

\section{Reference}

1. Li J, Li DE, Hu M, Huang H, Xu S, Li H (2021) Red blood cell distribution width and tumor necrosis factor-alpha for the early prediction of coronary artery lesion in Kawasaki disease: a retrospective study. Eur J Pediatr

Publisher's Note Springer Nature remains neutral with regard to jurisdictional claims in published maps and institutional affiliations.
Communicated by Peter de Winter

This reply refers to the comment available online at https://doi.org/ 10.1007/s00431-021-04361-z.

Huajun Li

lihuajun@xinhuamed.com.cn

1 Department of Pediatrics, Division of Life Sciences and Medicine, Hospital of USTC, University of Science and Technology of China, No.17 Lujiang Road, Hefei, Anhui 230001, China

2 Department of Infectious, Xinhua Hospital, Shanghai Jiaotong University Medical College, No.1665 Kongjiang Road, Shanghai 200092, China 